\title{
BIOCHEMICAL CHANGES OF FOUR DIFFERENT COCONUT (COCOS nusifera L.) FORMS UNDER MOISTURE STRESS CONDITIONS
}

\author{
W.G.D. Lakmini ${ }^{1}$, N.P.A.D. Nainanayake ${ }^{2}$ and W.A.J.M. De Costa ${ }^{3}$
}

\begin{abstract}
Drought causes a substantial reduction in national yield of coconut and also a loss of coconut palms in severe droughts thus resulting in serious economic consequences to the coconut industry in Sri Lanka. Therefore, it is of prime importance to identify some putative drought tolerant forms to use in drought-prone areas. As the long generation and maturation periods of coconut restrict the selection of coconut forms based on yield, the knowledge on physiological and biochemical responses to water deficit conditions plays an important role in developing a rapid selection criterion. Therefore, the objectives of this research was to quantify the variations in drought tolerance in selected coconut forms, based on their biochemical responses to progressive soil moisture deficits in the field.
\end{abstract}

Four coconut forms (Clovis, Dwarf Green, Dwarf Brown, Cameron Red Dwarf) were selected for the experiment. Palms were subjected to 80-day natural drought experienced in early 2005. Biochemicals namely leaf proline, total soluble sugar and starch contents were studied during the drought period along with the corresponding soil moisture contents at 50 and $100 \mathrm{~cm}$ depths. They showed slightly increasing trends with progressive water stress but not significantly different in between four forms. However, duration of natural drought that occurred during the experimental period was shorter than the dry spells which are commonly observed in the area. Therefore, further research under long dry spells is needed to reach a more comprehensive and repeatable results before coming to a final conclusion.

Key words: Biochemical parameters, coconut, drought, proline,

\section{INTRODUCTION}

Coconut (Cocos nucifera L.) is the most widely grown plantation crop in Sri Lanka (Fernando, 1997) and Sri Lanka is the fourth largest coconut producing country in the world, occupying a total area of approximately 440,000 ha of land (Liyanage, 1999). The average annual per capita consumption by way of oil and fresh nuts is about 110 nuts (Fernando, 1997).

About $15 \%$ of coconut lands in Sri Lanka are at the dry zone, and $69 \%$ of lands are at the intermediate zone (Department of Censes and Statistics,
2002). Shortage of available soil water and high temperature are the main limiting factors to plants growing in these regions. Due to long maturation and generation period of coconut the adverse effects of drought persist for two and a half years (Rajagopal and Ramadasan, 1999) and a large number of coconut palms are annually lost due to drought making severe economic consequences to the coconut industry in Sri Lanka. Therefore, selection of drought tolerant coconut forms is very important.

Plants posses different mechanisms to withstand drought and osmotic adjustment in tissues is one such

${ }^{I}$ Department of Crop Science, Faculty of Agriculture, University of Ruhuna, Sri Lanka.

${ }^{2}$ Plant Physiology Division, Coconut Research Institute of Sri Lanka, Lunuwilla, Sri Lanka

${ }^{3}$ Department of Crop Science, Faculty of Agriculture, University of Peradeniya, Sri Lanka. 
mechanisms which maintain tissue turgor at a higher level even under the decreased total water potential during moisture stressed conditions (Taize and Zeiger, 1991). This happens due to active accumulation and synthesis of solutes within the cell. Sugars and amino acids are the major solutes responsible for osmotic adjustment (De Costa, 2001). There is an extensive body of literature showing correlation in between significant accumulation of certain substances and various measures of adaptability to drought such as yield, greater survival under drought and greater recovery from drought (Jharna et al, 2003). Yoshiba (1995) showed that the variation in accumulation of proline during drought could be used for screening the varieties for drought tolerant characters.

The basic physiological principle in drought studies of coconut is to look for the varieties which can conserve water and maintain leaf turgidity during adverse conditions. This can be assessed by investigating physiological and biochemical aspects of coconut under drought. Therefore, the objective of this study was to quantify the variation in drought tolerance in the four coconut forms, based on their biochemical responses to progressive soil moisture deficits in the field.

\section{MATERIALS AND METHODS}

The work was carried out at the Coconut Research Institute of Sri Lanka (CRISL). Four different coconut forms viz. Clovis $(C L)$, Sri Lankan Brown Dwarf $(D B)$, Sri Lankan Green Dwarf $(D G)$ and Cameroon Red Dwarf $(C R D)$ were selected for the field experiment. They were a part of the ex situ coconut gene bank, with approximately 15 years of age and planted at Poththukulam Research Station (PRS) which is situated in the $\mathrm{IL}_{1}$ (Semi-wet, intermediate low country region) agroecological region. All palms were under the general management practices recommended by CRISL, from the time of planting. Eight adjacent palms from each of four forms were selected from the experiment plots arranged in Completely Randomized Design $(C R D)$.

Biochemical measurements were taken once a month during the rainy season and the frequency was increased to once a week during the drought. Leaf samples taken from the middle portion of the ninth leaf from top (Braconnier and Bonneau, 1998) were used for all biochemical assays. Total sugar $(\mu \mathrm{g} / \mathrm{g}$ DW), starch ( $\mu \mathrm{g} / \mathrm{g}$ DW) (Dubois et al., 1956) and proline (mg/g DW) (Bates et $a l ., 1973$ ) content were assayed using oven dried, powdered leaf samples extracted in 80 per cent Ethanol.

Daily rainfalls (RF) (mm) data were obtained from the weather station maintained by the CRISL at PRS. Soil moisture content (\%) at the depth of 50 $\mathrm{cm}$ and $1 \mathrm{~m}$ was determined using gravimetric method at each measuring time simultaneously with other biochemical measurements. Preliminary data analysis for each parameter was conducted using Analysis of Variance (ANOVA) and the Duncan's New Multiple Range Test (DNMRT) was used as the mean separation technique to identify the differences between four coconut forms. 


\section{RESULTS AND DISCUSSION}

Palms were subjected to 80 -day natural drought period (i.e. from $18^{\text {th }}$ December 2004 to $7^{\text {th }}$ March 2005, the drought period represent from day 79 to 159 in graphs) with three brief sporadic rains (i.e. day 114,125 and 145) during the experimental period. The marked reduction in monthly rainfall from $416.22 \mathrm{~mm}$ in November to just $16.2 \mathrm{~mm}$ in January indicates the intensity of the drought of the area.

The soil was sufficiently wet due to the heavy rains received prior to the drought and the soil moisture content varied only from 9.2 to $10.8 \%$ among four plots of coconut forms prior to the drought which indicated that all palms were under more or less similar soil moisture conditions at the inception of the drought. Soil moisture content was reduced to levels as low as 3.5 to $2.5 \%$ during drought period.

The accumulation of proline, starch and total soluble sugars in the leaves of four coconut forms are shown in fig. 1, 2 and 3. A gradual increase in proline accumulation was observed during drought in relation to well-watered conditions (i.e. day 56). But the variations in between four forms were not statistically significant (Figure: 01 ) though the known degree of drought tolerance of those four forms at the field is varied.

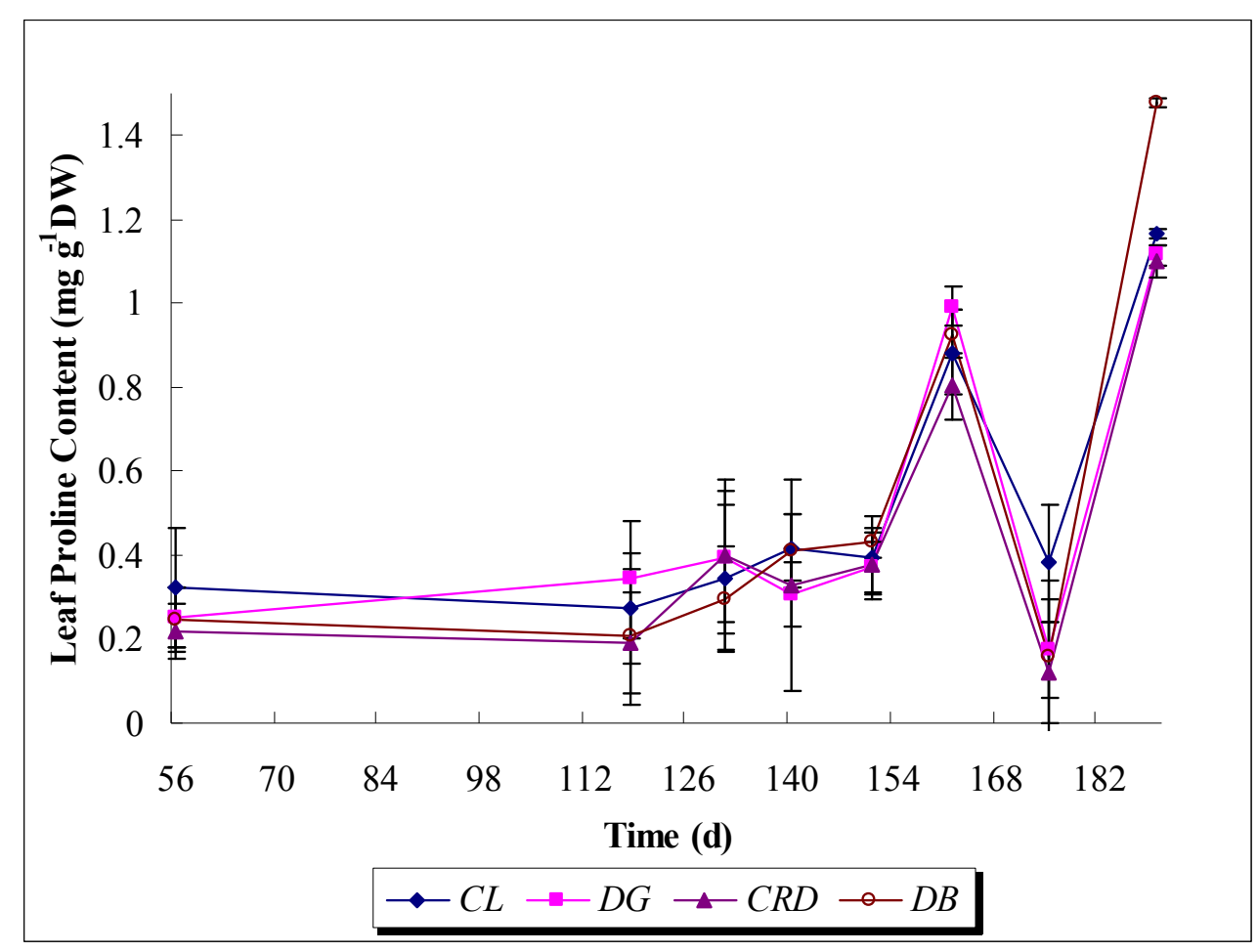

Figure 01: The effect of drought on leaf total proline content of individual leaves of four coconut forms. Each data point is mean of eight measurement, Error bars indicate the standard error of mean. 


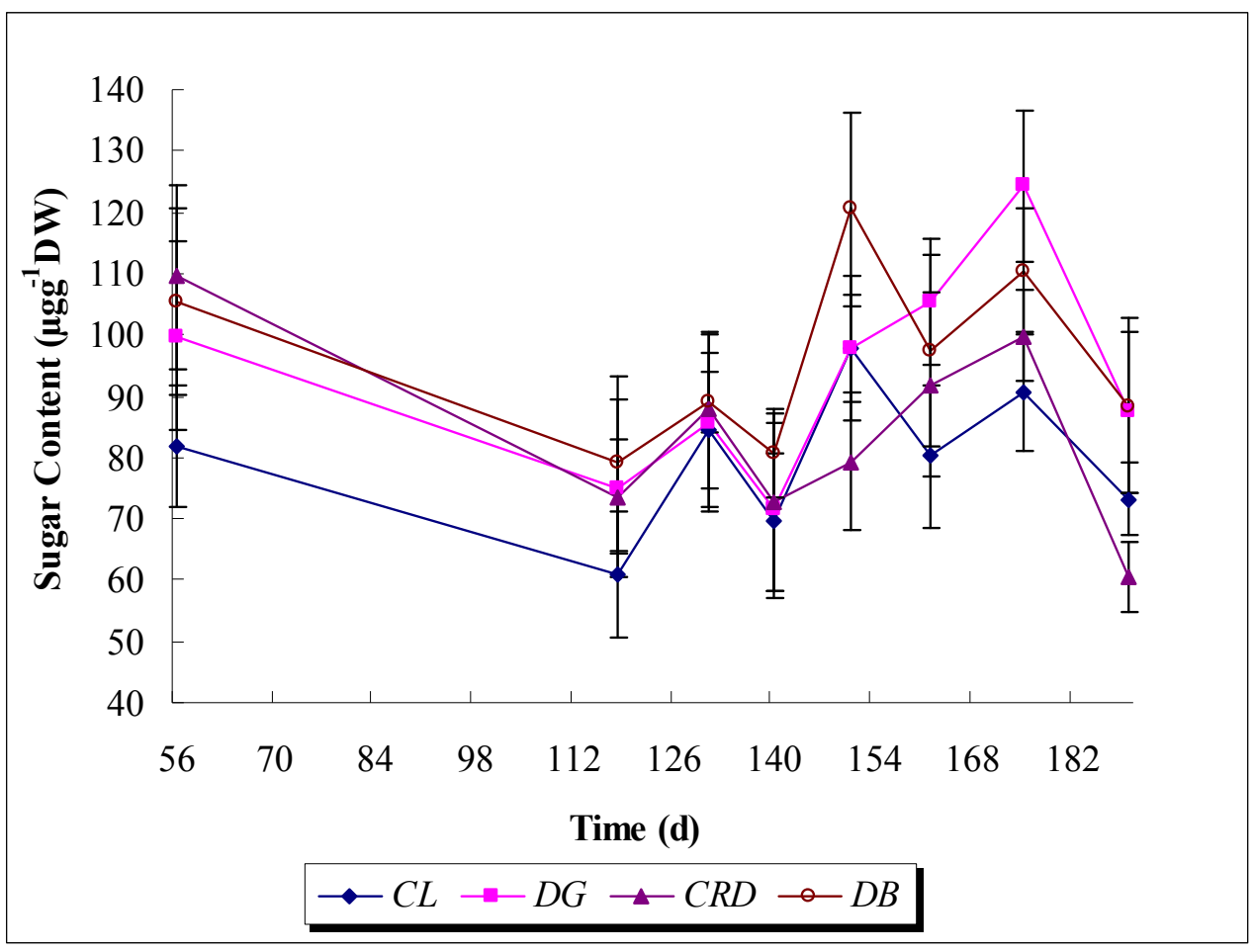

Figure 02: The effect of drought on leaf total soluble sugar content of individual leaves of four coconut forms. Each data point is mean of eight measurement, Error bars indicate the standard error of mean.

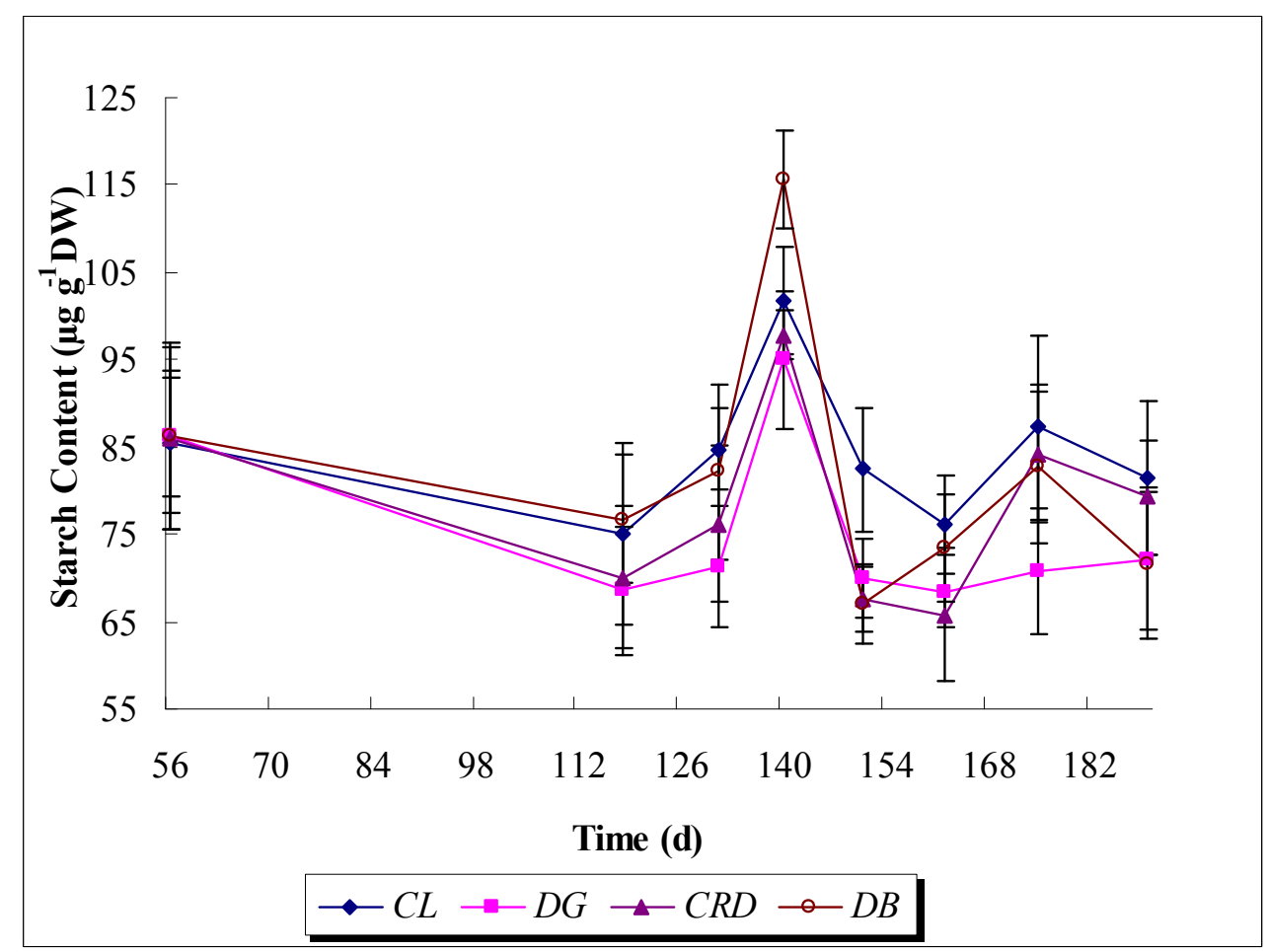

Figure 03: The effect of drought on leaf starch content of individual leaves of four coconut forms. Each data point is mean of eight measurement, Error bars indicate the standard error of mean. 
At the end of the drought a remarkable increase in proline can be observed and it suddenly reduced with the onset of rain again. However, Sean et al. (1998) showed that these solutes are normally accumulated slowly in response to tissue dehydration. Likewise, dissipation also takes place slowly. They observed 35 times increase in the concentration of the proline in Ber (Ziziphus mauritiana), which is a major fruit tree crop of the North-West Indian arid zone. This increase was shown during drought period of 13 days. In the present experiment, a 3-4 times increment of proline was observed in all forms. This may be either because of the low degree of moisture stress experienced by coconut palms during the experimental period and/or the prominent role-played by stomata regulating the water balance in coconut palms over osmotic adjustment.

An extensive body of literature shows the accumulation of proline under water stress conditions (Carceller et al., 1999, Hare et al., 1998, Jharna et al., 2003 and Sean et al., 1998). Plants, producing a higher amount of proline under water stress conditions may be considered as varieties with relatively greater drought tolerance (Jharna et al., 2003). Proline as a compatible solute can decrease water potential without decrease in turgor and also as an organic compound that do not interfere with enzyme activities (Taize and Zeiger, 1991). Therefore, variation in the accumulation of proline during drought stress could be used for screening varieties for drought tolerance. Carceller et al. (1999) observed drought tolerant lines of maize accumulate more proline and show more osmotic adjustment than drought susceptible lines. Sundaresan and Sudhakaran (1995) also observed a higher accumulation of proline in drought tolerant Cassava as compared to drought susceptible Cassava. Yet, there are different arguments of the role of proline in plant metabolic activities.

Besides the accumulation of specialized compounds, water stress is accompanied by a shift in the partitioning of photosynthates, such as sugars. Under moisture stress condition, increased levels of sucrose and/or reducing sugars have frequently been reported and have often been proposed to contribute towards the maintenance of turgor.

Hexose sugars (particularly glucose) have been reported as contributing directly to osmotic adjustment in several species including cottonwood, poplar, oak and pine (Sean et al., 1998). In the present experiment total soluble sugar content in a leaf was lower at the day 118 (first data set taken at drought) as compared to wellwatered conditions (i.e. day 56) in all four forms (Fig. 2). At the day 56 soluble sugars content of $C L$ differed significantly $(P<0.05)$ from that of $D B$, $D G$ and $C R D$. $C L$ showed a significantly lower soluble sugar content $(P<0.05)$ compared to the rest of forms at the early part of the drought (i.e. day 118). But at the end of the drought (i.e. day 151), the sugar content of $C L$ was second only to $D B$. Those results were tally with the known conditions of drought tolerance of $C L$ and $D B$ in the field. $C L$ is considered as most drought tolerant forms out of four while $D B$ shows some degree of tolerance for drought than other two dwarfs. With progressive drought there was no gradual increment in sugar content. 
Leaf starch content was also low at the day 118 than under well-watered conditions (Fig. 3). After that leaf starch content of four coconut forms increased up to day 140 then again showed rapid reduction. $C L$ and $D B$ maintained slightly higher leaf starch contents from day 118 to day 140 , while $D G$ maintained lowest rates. Meanwhile, the starch content of $D B$ at day 140 was significantly different $(P<0.05)$ from the other three forms. The accumulation of sugars and starch showed a greater variation than proline in present study. Therefore, the variation patterns of sugars and starch contents in different forms can be considered as sensitive indicators in screening different coconut forms for drought tolerance.

\section{CONCLUSION}

In the present experiment, investigated biochemical parameters showed only slight differences between four forms during the moisture stress period. However, there was an increasing trend in all four forms, which indicated some degree of osmotic adjustment in cell sap. The eighty-day drought period during which biochemical performance of coconut forms were evaluated, appeared not so critical for coconut palms. This was probably because of their general hardy behaviour and the drought-relieving effect of the brief rains experienced towards the end of the drought. Therefore, further research under longer dry spells is needed to reach a more comprehensive and repeatable results before applying these biochemical parameters as an index for screening drought tolerance in coconut.

\section{References}

Bates, L.S., R.P. Waldren and I.D. Teare (1973). Rapid determination of free proline for water stress studies. Plant Soil. 3a: 205-207.

Braconnier, S., X. Bonneau (1998). Effect of chlorine deficiency in the field on leaf gas exchanges in the PB121 coconut hybrid. Agronomie 18: 563-572.

Carceller, M., P. Pristupa and H. Lemcoff (1999). Remobilization of proline and other nitrogen compounds from senescing leaves of maize under water stress. $J$. Agronomy \& Crop science 183: 61-66.

De Costa, W.A.J.M. (2001). Plant water relations: Principles and Applications. Printing unit, University of Peradeniya, Sri Lanka.

Department of Censes and Statistics. (2002). Agriculture survey.

Dubois, M., K.A. Gilles, J.K. Hamilton, P.A. Robers and F. Smith (1956). Colorimetric method for determination of sugars and related substances. Anal. Chem. 28: 350-356.

Fernando, W.M.U. L. Perera and R.A. Peries (1997). An Overview of Breeding Research in Coconut- the Sri Lankan Experience. Outlook on Agriculture 3: 191-198.

Hare, P.D. W.A. Cress and J. Van staden (1998). Dissecting the role of osmolyte accumulation during stress. Plant Cell and Environment 21: 535-553.

Jharna, D.E., B.L.D. Chowdhury, M.A. Haque, M.R.H. Bhuiyan and M.M. Husain (2003). A preliminary investigation of the proline content and nitrate reductase activity of some groundnut genotyps as index of screening for drought tolerance. Bangladesh J. Agril. Res. 28(2): 283-290. 
Liyanage, M.de S. (1999). A guide to scientific cultivation and management of coconut. Hitech Prints, Nugegoda.

Rajagopal, V. and A. Ramadasan (1999). Advances in plant physiology and biochemistry of coconut palm. APCC. 80-81.

Sean, C. C., K.A. Stefan, E.C. Janet, J. Sangeeta, S. Narendra, P. Marianne and G.J. Hamlyn (1998). The role of solute accumulation, osmotic adjustment and changes in cell wall elasticity in drought tolerance in Ziziphus mauritiana (Lamk.). Jornal of Experimental Botany 19. No. 323, 967-977.

Sundaresan, S. and P.R. Sudhakaran (1995). Water stress induced alteration in the proline metabolism of drought susceptible and tolerant Cassava (Manihot esculanta) cultivars. Physiol. Plant. 94: 635-642.

Taize, L and E. Zeiger (1991). Plant physiology. The Benjamin/Cummings publishing company, Inc. California. 346-356.

Yoshiba. (1995). Correlation between the induction of gene for pyrroline-SCarboxylate synthatase and the accumulation of proline in Arabidopsis thahniana under osmotic stress. Plant J. 7: 551-760. 